\title{
EXHIBITION
}

\section{Classifying the past}

The photograph of artist Mark Dion
included in hislatest exhibition,
Microcosmographia, is strikingly
similarto one of the American
naturalist William Beebe taken in
1917. This isno accident: Dion's
adoption of the attitudes and
methods of such early naturalists
is very deliberate. Through
Microcosmographia, Dion
highlights problems of accuracy,
past and present, in natural history
and taxonomy.
The exhibition's central piece,
Ichthyosaur, pictured here,
references the confusion of
palaeontological classification
in the early nineteenth century.
Variously misinterpreted by fossil
collectors and palaeontologists as
prehistoric fish, predecessors of
modern crocodiles, or relatives of
the duck-billed platypus, the genus
Ichthyosaurwas only officially
designatedas such by William
Daniel Conybeare in 1822 .
The belly of Dion's life-size resin
replica of a beached ichthyosaur
is split open and over flows with

the paraphernalia of early naturalists, ranging from old reference manuals to glass beakers. The work seems to suggest that the ichthyosaur is a creature quite literally made up of the past; that its inner workings are defined by the humans who discovered it and eventually classified it. The conceptresonates with presentday taxonomy, which is struggling to systematize 250 years of natural history of varying scientific quality: sifting out errors, identifying missed connections, and establishing a comprehensive informatics for the field.

Confusions and corrections, such as those surrounding the ichthyosaur, inspire Dion's work. The diverse collection of sculptures, drawings and photographs in this exhibition, and their juxtapositions and groupings, focus on long-dead scientists and their influences on scientific understanding today. But the collection also raises important

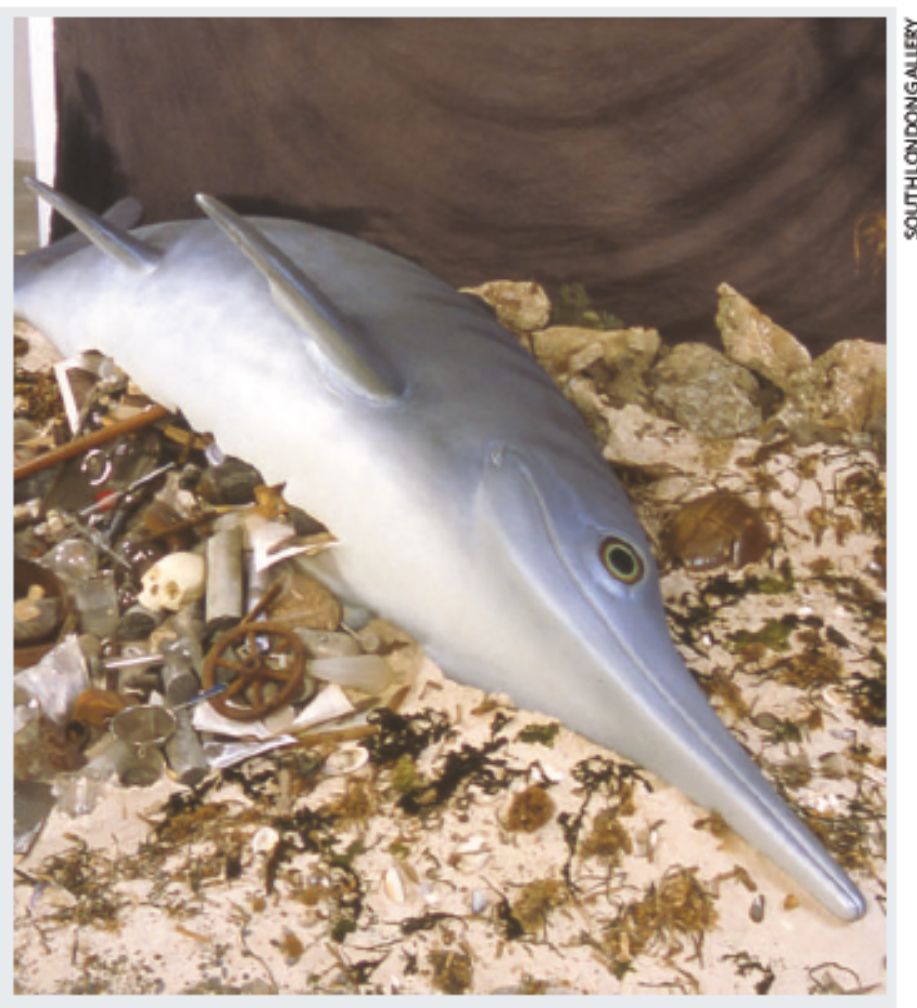

questions about the fallibility of science. Dion seems to want to pointout the mistakes of the past in order to warn us aboutmistakes we might be makingnow, and mightmake in the future.
Microcosmographia, organized by the South London Gallery, can be seen at The Harris Museum and Art Gallery in Preston, UK, until 12 March 2006.

Alexis Clements
Martin Davis in the early 1950s. In Meta Math, Chaitin has extended this line of thought by using the notion of the computer program to study incomplete mathematical theories. Written for the general reader, the book consists of a main text of about 160 pages, followed by reprints of two earlier papers of a more technical character.

A key notion in this book, inspired by biology, is the 'complexity' of a program, specified in terms of the smallest program(s) (in bit size) that can produce some given output. Such a program is irreducible, or incompressible: "So you can define randomness as something that cannot be compressed at all," according to Chaitin. Thence follows the Omega number, an infinitely complex positive real number specifying the halting probability. As Chaitin puts it, it is defined from all the programs chosen by chance to run on a fixed computer and also to continue to run by random operator decisions until the computer "must decide by itself when to stop reading the program"; if a program halts after $k$ bits, then it contributes $1 / 2^{k}$ to the number. As stated, the number depends on the computer used; presumably this machine is Turing-powerful enough to run any program installed on it. Drawing upon a discussable daim that any mathematical theory can be encoded in programming terms, Chatin concludes that the Omega number "marks the current boundary of what mathematics can achieve".

Chatin's investigation is attended by several skirts around paradoxes, especially those involving naming. For example, to qualify as a program contributing to the Omega number, the program has to be able to say how large it is when it halts. This type of concern also owes much to Godel's 1931 theorem, where new standards were imposed on distinguishing logic from metalogic. It is a pity that Chaitin never states that theorem precisely, and once even states it quite wrongly.

The scope of the author's meta-programme (as it were) is impressive: essentially straightforward assumptions and steps lead to some wide-ranging consequences and claims about mathematics, logic and computing science. The account is nicely signposted by the frequent use of information boxes containing the main definitions, steps or relationships. As the book is intended for a wide audience, it might have been enriched by some comments on concurrent developments that have used versions of the main notions, for example, (non-biological) complexity with A. N. Kolmogorov in the $1960 \mathrm{~s}$, or the realm of intelligent activity lying beyond computability, as debated by Roger Penrose and others in recent times.
The style of writing throughout is better suited to an internet chatroom than to a book ( ${ }^{\alpha}$ Discours de Métaphysique — that's the original French" is only one such example) and has exclamation marks spread liberally. Instead of properly referencing works that are precisely cited in the text, " $\mathrm{I}$ decided to concentrate mostly on recent books that caught my eye," says the author. The list lacks, among other key works, J. W. Dawson's Logical Dilemmas, The Life and Work of Kurt Godel (A. K. Peters, 1997) and The Essential Turing edited by B. J. Copeland (Oxford University Press, 2004).

Many historical remarks are made, but are seemingly free of knowledge of the figures involved and their importance. For example, "the nearly-forgotten 17th-century genius Leibniz", "Newton's incomprehensible Principia - written in the style of Euclid's Elements", or "it was Cantor's obsession with God's infiniteness and transcendence that led him to create his...theory of infinite sets and infinite numbers". The reader should be ready to add their own exclamation marks to such passages.

It is nice to have popular books on modern mathematics, logic and science. But it is nicer if they are prepared with care. Ivor Grattan-Guinness is at Middlesex University, Enfield, Middlesex EN3 4SF, UK. 